\title{
A ENFERMAGEM DE SAÚDE PÚBLICA NO DISTRITO FEDERAL: A INFLUÊNCIA DO RELATÓRIO GOLDMARK (1923 A 1927)a
}

\author{
The Public Health Nursing in the Distrito Federal: \\ The Influence of the Goldmark Report (1923 to 1927) \\ La Enfermería de Salud Publica en el Distrito Federal: \\ La Influencia del Relato Goldmark (1923 hasta 1927)
}

Mary Ann Menezes Freire ${ }^{1}$

Wellington Mendonça de Amorim²

\begin{abstract}
Resumo
Estudo histórico-social, embasado na análise documental. Investiga as influências do Relatório Goldmark na organização da enfermagem de saúde pública, após o processo da Reforma Carlos Chagas, de 1923 a 1927. Objetivos: identificar as circunstâncias em que se deram as primeiras propostas para organizar a enfermagem de saúde pública durante a Reforma Carlos Chagas; analisar as implicações do Relatório Goldmark para a organização do saber e do fazer na enfermagem de saúde pública, na Capital da República, na década de 1920. Podemos citar como uma das implicações do Relatório Goldmark na organização da enfermagem de saúde pública no Distrito Federal a alteração do Standard Curriculum, adotado pela Escola de Enfermagem do Departamento Nacional de Saúde Pública, diante de uma de suas questões centrais, que procurou produzir um equilíbrio no ensino teórico-prático, o que provocou reflexos no saber e no fazer das enfermeiras de saúde pública.
\end{abstract}

Palavras-chave: História da Enfermagem. Saúde Pública. Política de Saúde.

\begin{abstract}
Study of historic-social nature based on documental analysis. About the influences of Goldmark's Report about the organization of nursing in public health after the process of Carlos Chagas's Reform, 1923 - 1927. Objective: To identify the circumstances in which occurred the first proposals to organize the nursing of public health during the Carlos Chagas's Reform; To analyze the implications on Goldmark's Report for the organization of knowing and doing in nursing of public health, in the Republic's Capital on the decade of 1920. We can mention, as one of the implications of Goldmark's Report on the nursing of public health organization in the "Distrito Federal", the change of Standard Curriculum that was adopted by School of Nursing of National Department of Public Health face to the one of their central questions that was intended to create a balance in the theoretical-practical teaching, that surely would arise reflection in the knowing and doing of the public health's nurses.
\end{abstract}

Keywords:

History of Nursing. Public Health. Health Policy.

\section{Resumen}

Estudio histórico-social basado en el análisis documental. Investiga las influencias del Relato Goldmark en la enfermería de salud publica después del proceso de la Reforma Carlos Chagas, 1923 - 1927. Objetivos: Identificar las condiciones en que ocurrieron las primeras propuestas para organizar la enfermería de salud publica en la Reforma Carlos Chagas; Analizar las implicaciones del Relato Goldmark para la organización de lo saber y de lo hacer en la enfermería de salud publica en la Capital de la Republica en la década de 1920. Podemos citar cómo una de las implicaciones del Relato Goldmark en la organización de la enfermería de salud publica en el Distrito Federal la alteración del "Standart Curriculum", adoptado por la Escuela de Enfermería del Departamento Nacional de Salud Publica, frente una de sus cuestiones centrales que intentó producir un equilibrio en la enseñanza teórica y practica, lo que causó reflejo en lo saber y el que hacer de las enfermerías de salud pública.

Palabras clave:

Historia de la Enfermería. Salud Pública. Política de Salud. 


\section{INTRODUÇÃO}

Este estudo trata das influências do Relatório Goldmark na organização da enfermagem de saúde pública, após o processo da Reforma Carlos Chagas, de 1923 a 1927.

0 recorte temporal compreende como marco inicial o ano de 1923, que demarcou a publicação do Relatório Goldmark, e como marco final o ano de 1927, quando ocorre a revisão do Standard Curriculum da Escola de Enfermeiras Dona Anna Nery, do Departamento Nacional de Saúde Pública (DNSP), atual Escola de Enfermagem Anna Nery, da Universidade Federal do Rio de Janeiro.

No final da primeira década do século XX, a saúde no Brasil se encontrava diante da total ineficácia dos serviços públicos e se deparava com as grandes epidemias e endemias que afligiam o Rio de Janeiro ${ }^{1: 73}$. Mesmo diante desta situação, as ações sanitárias estavam restritas a momentos de crise (endemias, epidemia e guerra). A história da saúde pública aponta que no início do século XX, as ações mais contundentes de combate às doenças ocorreram na gestão de Oswaldo Cruz na Diretoria Geral de Saúde Pública, no governo de Rodrigues Alves. No entanto, a preocupação por parte de alguns governantes da Primeira República se mostrou inconstante com relação à prevenção e controle das situações, o que só viria a acontecer, como política do setor, a partir da década de 1920.

A primeira Comissão da Fundação Rockefeller (FR) chegou ao Brasil em 1915, com a presença de Wickliffe Rose, diretor da International Health Commission que, a partir de 1916, passou a se chamar International Health Board (IHB) e que desempenhou papel de destaque na condução das atividades da Rockefeller no Brasil, para coletar informaç̧ões e identificar áreas de atuação, fato este que estreitou relações e abriu caminho para a entrada de médicos e sanitaristas norte-americanos da Rockefeller no país. A Missão Médica da Rockefeller chegou ao Rio de Janeiro em setembro de 1916, a convite de Nilo Peçanha, então governador do Estado do Rio de Janeiro, com o objetivo de diagnosticar, prevenir e combater as endemias ${ }^{2}$.

Diante das evidências e necessidades de uma reforma sanitária, em 1920, foi criado o DNSP. Neste mesmo ano, o sanitarista Carlos Chagas se torna diretor do DNSP, concretizando-se o que mais tarde denominaríamos de Reforma Carlos Chagas ${ }^{3: 22}$. A Reforma se amparou em dois Decretos, $\mathrm{n}^{\circ}$. 3.987 de 02 de janeiro de 1920 e n ${ }^{\circ} .14 .354$ de 15 de setembro de $1920^{4,5}$, que dispuseram sobre a criação e regulamentação do DNSP, caracterizando, assim, a presença do Estado brasileiro na reorientação da política de saúde, a partir da centralização das ações no campo da saúde pública em um Departamento.

Em 1921, após o pedido de apoio de Carlos Chagas à IHB para implantação do Serviço de Enfermeiras no Brasil, a Rockefeller criou uma Missão de Cooperação Técnica para o Desenvolvimento da Enfermagem no Brasil, para levar adiante as reformas necessárias à implantação do serviço: ${ }^{6: 130}$.

Com isso, ainda em 1921, a enfermeira americana Ethel Parsons veio ao Brasil para a criação de um serviço de enfermeiras no DNSP e de uma escola de enfermeiras. Esta estratégia ficou conhecida como Missão Parsons e atuou no Brasil durante dez anos consecutivos (1921 - 1931), com 0 patrocínio da $\mathrm{FR}^{7: 66}$. Como solução provisória, e para assegurar a criação da escola, em 1922, foi criado um curso de emergência com seis meses de duração, para ampliar o quadro das visitadoras e manter o controle sanitário da população: ${ }^{8}$.

Em 19 de fevereiro de 1923, é inauguradab , então, a Escola de Enfermeiras do DNSPc:

A criação de uma escola de enfermagem e a delimitação de um campo de prática profissional constituíram prérequisitos necessários para que fossem retirados do cenário os visitadores de saúde, regulamentando-se, ao mesmo tempo, a enfermagem como profissão estratégica na organização da cidade $e^{9: 622}$.

A introdução do "Sistema Nightingale" no Brasil ocorreu, portanto, em 1923 por meio da criação da Escola de Enfermeiras do DNSP e com o auxílio de enfermeiras norteamericanas, e foi para aqui transplantado o programa vigente nos Estados Unidos, onde já havia sido modificado o currículo, de acordo com as conveniências das instituições mantenedoras das escolas, hospitais particulares em sua grande maioria ${ }^{10: 11}$. A criação desta escola de enfermeiras constituiu, de fato, o início de uma nova etapa para a enfermagem brasileira ${ }^{10: 26}$. E, com a diplomação da primeira turma de enfermeiras, em 1925, parte delas começaram a atuar nas visitas domiciliares, aperfeiçoando e ampliando o trabalho que já havia sendo executado ${ }^{11: 05}$.

0 Brasil na Primeira República era um país predominantemente agrícola, tendo como mais importante produto brasileiro de exportação o café. Foi apenas na década de 1920 que começaram a aparecer tentativas de superar os limites de expansão industrial. É comum denominar a Primeira República "república dos coronéis". 0 coronelismo representou uma variante de uma relação sociopolítica mais geral (o clientelismo). E essa relação resultava da desigualdade social, da impossibilidade de os cidadãos efetivarem seus direitos, da precariedade ou inexistência de serviços assistenciais do Estado ${ }^{12: 139.83}$.

Vários fatores concorreram para a emergência do projeto de organização sanitária nacional no início da década de 1920. Deve ser ressaltado o contexto de crescente agitação política das classes trabalhadoras e médias urbanas e as intensas repercussões da Primeira Guerra Mundial no país. No entanto, a ocorrência, em fins de 1918, da Gripe Espanhola foi o principal fator que assinalaria a extensa crise sanitária da época. Os serviços de assistência sanitária falhavam: não havia médicos, nem remédios. A falta absoluta de recursos médicos denunciava a desorganização dos serviços de saúde pública. A criação do DNSP e a organização da Missão Parsons seriam, assim, conseqüências desses movimentos que marcaram a sociedade brasileira em fins da década de 1910. Em 1923, como aparente desdobramento do movimento articulado em torno da extinta Liga Pró-Saneamento do Brasil, os intelectuais da saúde pública criam a Sociedade Brasileira de Higiene, cuja presidência foi usualmente exercida pelo diretor do DNSP, e cuja função seria atuar como linha auxiliar deste Departamento ${ }^{13: 81-99}$.

Concomitantemente ao processo da Reforma Carlos Chagas, foi produzido nos EUA o Relatório Goldmark, a partir de 1919. Com o crescente interesse da Fundação Rockefeller nas questões de saúde pública, cria-se uma comissão cujos objetivos 
inicialmente foram focados em enfermagem de saúde pública. Mais tarde, em fevereiro de 1920, a Fundação Rockefeller ampliou o objetivo da pesquisa, incluindo "um estudo da totalidade da educação em enfermagem, com vistas ao desenvolvimento de um programa para estudos posteriores e recomendações para o futuro" $14 ; 12$.

Elaborado por um comitê especialmente criado para o estudo da Educação em Enfermagem, o produto gerou um impacto em âmbito mundial, vindo a influenciar o estabelecimento e a evolução de um modelo de enfermagem anglo-americano. Este modelo seria implantado no Brasil em 1923, mesmo ano de publicação do Relatório, na Escola de Enfermeiras do Departamento Nacional de Saúde Pública ${ }^{14}$.

A National League of Nursing Education, liga constituída por diretoras de escolas dos Estados Unidos e do Canadá, tinha como propósito principal tentar exercer controle sobre o ensino de enfermagem naqueles países e foi a responsável também por modificações importantes no currículo de enfermagem. Publicou, em 1917, uma obra que tratava especificamente do ensino da enfermagem, o "Standard Curriculum for Nursing Schools", a primeira tentativa concreta para a padronização dos currículos das escolas ${ }^{10}$.

Em 1927, o Standard Curriculum foi revisto, tendo sido introduzido, dentre outras determinações, um aumento no total de aulas teóricas, restringindo-se o período de prática. Tal revisão sofreu a influência das recomendações contidas no Relatório Goldmark ${ }^{10: 22-23}$.

Diante da importância dos fatos acima citados para a enfermagem de saúde pública, torna-se oportuno estabelecer uma melhor compreensão acerca da trajetória da nossa profissão, cuja reflexão,

"necessária à formação de uma consciência crítica, além do conhecimento da história da enfermagem brasileira, que faz parte da cultura profissional de cada qual, depende também do interesse e da consciência que nós, mulheres e homens de algum modo envolvidos, tivermos das relações passado/presente, o que faz com que valorizemos nossos papéis históricos, como observadores atentos dos sinais de nossa época, como pessoas que nos empenhamos em formar uma opinião esclarecida, como atores que participam do movimento da história e como estudiosos que pretendem contribuir para a compreensão do que nos ocorreu e do que nos ocorre, posto que (parafraseando Hobsbawm), somos parte dessa história e ela é parte de nós"15: 92.

Oconhecimento acerca denossa história não só permite desenvolver uma consciência mais crítica, como proporciona uma melhor compreensão do presente. E o historiador de enfermagem, por suavez, é quem contribui para este conhecimento, produzindo-o.

No início da década de 1920, as atividades de enfermagem de saúde pública eram realizadas pelas visitadoras domiciliares, cujo trabalho era caracterizado pelo esforço em educar as famílias para melhores condições de saúde e ainda realizar "cuidados de cabeceira" daqueles que elas encontravam enfermos. Assim, sobre as visitas domiciliares, sua realização "dependia de um grande investimento pessoal, visto que o trabalho era insalubre, desgastante, difícil, não tinha remuneração compensadora nem recompensas sociais e ainda enfrentava as resistências das famílias"1:77.
A conjugação de forças e interesses da Fundação Rockefeller, do DNSP (como estrutura de Estado), dos sanitaristas e das enfermeiras norte-americanas, e da Reforma Carlos Chagas, gerou as condições objetivas para iniciar, pela primeira vez na história da saúde pública brasileira, uma iniciativa capaz de organizar, sob a ótica da enfermagem moderna, a enfermagem de saúde pública, no âmbito de um departamento de estado.

Desse modo, considerando a política de saúde brasileira da época, a presença e a atuação da FR junto à reorganização do DNSP e a publicação do estudo da Educação em Enfermagem norte-americana, denominado Relatório Goldmark, é que buscamos, a partir de informações documentais, elucidar questões referentes à organização da enfermagem de saúde pública no início da década de 20 do século XX no Distrito Federal.

Para operacionalizar o estudo, foram definidos os seguintes objetivos:

1. Identificar as circunstâncias em que se deram as primeiras propostas para organizar a enfermagem de saúde pública durante a Reforma Carlos Chagas;

2. Analisar as implicações do Relatório Goldmark para a organização do saber e do fazer na enfermagem de saúde pública na Capital da República na década de 1920.

0 estudo integra a linha de pesquisa: As políticas de saúde no contexto histórico social e suas implicações para a enfermagem de saúde pública no Brasil, do grupo de pesquisa do $\mathrm{CNPq}$ "A trajetória da enfermagem de saúde pública no Brasil", desenvolvido no Laboratório de Pesquisa em História da Enfermagem - Laphe - EEAP, da Universidade Federal do Estado do Rio de Janeiro (UNIRIO).

0 ofício do historiador não é somente "o de lembrar o que os outros se esquecem", mas principalmente o de "compreender e explicar porque as coisas deram no que deram e como elas se relacionam entre si". A principal tarefa do historiador "não é julgar, mas compreender, mesmo o que temos mais dificuldade para compreender"15:87. Desse modo, o produto deste estudo busca novas questões no interior dos fatos e fenômenos oriundos dos modelos que influenciaram a enfermagem de saúde pública, além de contribuir para a produção científica da História da Enfermagem.

\section{MÉTODO}

Trata-se de um estudo de natureza histórico-social, cujo desenvolvimento apoiou-se na análise documental. Consideraram-se como documentos os registros escritos que puderam ser utilizados como fonte de informação e que através dos quais pudéssemos identificar princípios e regras que regessem as relações que se estabeleceram entre os diferentes grupos $^{16: 169}$. No entanto, os documentos não foram vistos apenas como fonte de informação, mas como algo que pudéssemos analisar, interpretar e compreender, para a produção de novos conhecimentos. Assim, a proposta para as análises de documentos em pesquisa histórica é a de que um texto seja sempre portador de um discurso e que, assim considerado, não poderá ser visto como algo transparente ${ }^{17: 377}$.

Como fontes primárias, foram utilizados leis, decretos, relatórios e publicações, explorados nos seguintes acervos: Centro de Documentação da Casa de Oswaldo Cruz - Fiocruz - 
Manguinhos, RJ; Arquivo Setorial Maria de Castro Pamphiro EEAP - UNIRIO; Biblioteca do Ministério da Fazenda, RJ; Centro de Documentação da Escola de Enfermagem Anna Nery UFRJ. Definimos como corpus documental: o Relatório Goldmark (1923); os Decretos de Criação e Regulamentação do Departamento Nacional de Saúde Pública (Decreto n 3.987, de 02 de janeiro de 1920; Decreto $n^{\circ}$. 14.354, de 15 de setembro de 1920); o Regulamento do Departamento Nacional de Saúde Pública (Decreto n . 16.300 - 1923); o livro Saneamento do Brasil de Belisário Penna (1923); e o Relatório das Modificações no Serviço de Enfermeiras do DNSP (1926 - 1930).

As fontes secundárias referiram-se à História do Brasil, à Política de Educação e Saúde, à História da Enfermagem Brasileira e à História da Enfermagem Norte-americana.

A análise e interpretação das informações são realizadas através da busca de nexos entre as informações obtidas nos documentos e a produção historiográfica do tema em questão ${ }^{18: 93}$. Assim definimos como unidades de análise as propostas do Relatório Goldmark e a organização da enfermagem de saúde pública no DNSP.

\section{AS CIRCUNSTÂNCIAS DA ORGANIZAÇÃO DA ENFERMAGEM DE SAÚDE PÚBLICA DURANTE A REFORMA CARLOS CHAGAS}

No mundo, 0 ano de 1918 foi marcado pelo fim da Primeira Guerra Mundial (1914 - 1918), que foi, efetivamente, a primeira guerra generalizada, envolvendo as principais potências, e cujas conseqüências afetaram todo o mundo ${ }^{\text {19:418-20. }}$.

0 Brasil era um país predominantemente agrícola, mas 0 predomínio das atividades agroexportadoras, durante a Primeira República, não foi absoluto ${ }^{12: 159}$.

Durante boa parte do século XX expande-se a industrialização do Brasil. 0 Sudeste apresenta-se como 0 locus privilegiado para a expansão de um parque industrial, caracterizando, assim, fortemente, as desigualdades regionais. Baixos salários, precárias condições de vida, grande freqüência de doenças, fruto da desnutrição e da insalubridade, elevada taxa de mortalidade, péssimas condições de moradia são 0 retrato da condição do trabalhador e dão uma idéia sobre a base da acumulação de capital no país 20: 245-50.

Outro acontecimento marcante foi a ocorrência, em fins de 1918, de uma extensa crise sanitária, provocada pela epidemia de gripe espanhola, que assinalaria que as condições de vida das camadas populares urbanas atingiram níveis baixíssimos. A crise nas condições sanitárias da população atingiu o núcleo econômico e político da República, a cidade do Rio de Janeiro e praticamente todos os centros econômicos de alguma importância ${ }^{13}$. A capital do país, entre outubro e dezembro, desorganizou-se completamente. Além de causar um grande número de mortes, a epidemia paralisou a vida da cidade, que sofria com a falta de alimentos e remédios, a carestia e a completa incapacidade das autoridades públicas em responder adequadamente ${ }^{21}$.

A gripe espanhola acentuou a crise nas condições de existência da população do Rio de Janeiro: em apenas dois meses morreriam 12.830 pessoas. A crise sanitária assinalaria igualmente as penosas condições em que se realizou o processo de industrialização e urbanização no país: nem um terço da população escapou de ser atingida pela enfermidade ${ }^{13: 93}$. É importante, então, perceber a epidemia como uma experiência coletiva singular que, por isso, teve impactos significativos sobre a política de saúde ${ }^{21}$.

A campanha pelo saneamento do Brasil, iniciada de forma não organizada em 1916, foi ampliada a partir de 1918, com a criação da Liga Pró-Saneamento do Brasil, tendo impactos significativos na sociedade brasileira. 0 tema do saneamento e da saúde pública ganhou as páginas dos jornais e a tribuna do Congresso Nacional. A saúde se tornara uma questão central no debate político nacional, em grande parte moldado a partir dos argumentos dos militantes desse movimento ${ }^{22}$.

Em 1918, Belisário Pena publica Saneamento do Brasil, onde aponta as falhas mais graves das politicas de saúde da época. Pena conclui que, à exceção de São Paulo, e em certa medida Minas Gerais e Rio Grande do Sul, os estados brasileiros só cuidavam das condições sanitárias das capitais e de algumas poucas cidades ${ }^{23}$.

É válido destacar a Escola Prática de Enfermeiras da Cruz Vermelha Brasileira, que, após a guerra, atuou principalmente no atendimento a situações de emergência, epidemias (como a gripe espanhola), além de outros desastres ou catástrofes. Também mantinha hospitais e cursos de voluntários ${ }^{24}$.

0 ano de 1919 mal começara e a gripe espanhola vitimava, em 16 de janeiro, o presidente eleito Rodrigues Alves. A morte do presidente demonstrava, de forma trágica, que representantes de ambos os lados do debate teriam razões suficientes para desconfiar e considerar falida a atuação federal na área de saúde. A morte de Rodrigues Alves revelava uma das faces do estado sanitário do país. Ao atingir também o presidente, a epidemia gerou um consenso sobre a necessidade urgente de mudanças na área de saúde pública, promovendo uma consciência sobre a necessidade de soluções amplas e de largo alcance ${ }^{21}$.

Após a Primeira Guerra Mundial, a presença da classe média urbana na cena política se tornou mais visível. De um modo geral, esse setor da sociedade tendia a apoiar figuras e movimentos que levantassem a bandeira de um liberalismo autêntico. Isso significava, entre outras coisas, eleições limpas e respeito aos direitos individuais. Falava-se nesses meios de reforma social, mas a maior esperança era depositada na educação do povo, no voto secreto, na criação de uma Justiça Eleitoral. Um indício da maior participação política da população urbana foi a eleição de 1919. Rui Barbosa, candidato derrotado em 1910 e 1914, apresentou-se à eleição, enfrentando Epitácio Pessoa; venceu o segundo 12: 171.

Epitácio Pessoa, recém-empossado, sugeria a criação de um Ministério da Saúde e Instrução Pública. Mas, sabedor das dificuldades, aceitava uma reforma que ampliasse os serviços sanitários federais. Argumentava que a medida não implicaria sobrecarga no orçamento da União, já que os serviços dispersos em vários ministérios seriam reunidos no novo órgão, além de ser criado um Fundo Sanitário. Influenciado pela campanha do saneamento, Pessoa defendia alguma forma de centralização dos serviços sanitários ${ }^{22}$.

A Câmara dos Deputados, que um ano antes, através da sua Comissão de Saúde Pública, vetara o projeto de criação do 
Ministério da Saúde do deputado Azevedo Sodréd, em 1919 aprovava um substitutivo a uma mensagem de Epitácio Pessoa criando o Departamento Nacional de Saúde Pública com atribuições e mecanismos de financiamento mais amplos do que aqueles propostos por Sodré21.

Em 2 de janeiro de 1920, por Decreto $n^{\circ} 3.987$, foram reorganizados os serviços sanitários federais, sendo realmente criado, então, o DNSP, regulamentado em setembro do mesmo ano pelo presidente Epitácio Pessoaa ${ }^{25: 08}$. A criação do DNSP seria assim conseqüência desses movimentos que marcaram a sociedade brasileira em fins da década de $1910^{13}$. 0 sanitarista e cientista Carlos Chagas foi nomeado diretor geral do Departamento, passando a acumular a direção do Instituto Oswaldo Cruz com a do DNSP, caracterizando, assim, a Reforma Carlos Chagas: ${ }^{8: 11}$.

Vale ressaltar que o ano de 1920 marcou o início da nacionalização das políticas de saúde e saneamento e da definição de uma nova identidade profissional para um grupo de médicos e de profissionais de saúde pública, vinculados à administração pública ${ }^{22}$.

Para o sanitarista JP Fontenelle, a ida de Carlos Chagas aos Estados Unidos, a convite da Fundação Rockefeller, em 1921, possibilitou compreender o valor da grande instituição da enfermeira visitadora, desenhando-se a possibilidade magnífica da cooperação com aquela Fundação ${ }^{25: 13}$.

Carlos Chagas solicitou, então, ao International Health Board que fosse organizado um serviço de enfermagem no DNSP, e, então, através da FR, foi criada a Missão de Cooperação Técnica para o Desenvolvimento da Enfermagem no Brasil, patrocinada pela $F R$, que promoveu inovações no DNSP, efetivando a Reforma Carlos Chagas ${ }^{8: 11}$.

Em 1922 o Brasil inicia uma fase política bastante agitada. A disputa eleitoral pela sucessão de Epitácio Pessoa foi conflituosamente intensa. Os candidatos, Artur Bernardes (eixo São Paulo-Minas) e Borges de Medeiros (Rio Grande do Sul), foram lançados em 1921, e o processo de eleição ocorreu em março de 1922, com a vitória de Bernardes, que assumiu apenas em novembro. Os conflitos que marcaram a disputa eleitoral precipitaram a eclosão do movimento tenentista, que seria apenas uma das características marcantes do governo de Artur Bernardes, que estava apenas começando ${ }^{12}$.

Foi delineada, pela recém-criada Missão de Cooperação Técnica, a execução de um curso intensivo de emergência, de seis meses, para formar Visitadoras de Higiene, seguido, depois, de um outro curso, de dez meses, enquanto se organizava definitivamente a Escola de Enfermeiras. 0 primeiro curso de emergência começou a funcionar em abril de 1922. Neste ano, também foi criado o Serviço de Enfermeiras, sob a superintendência da Sra. Parsons ${ }^{25: 13}$.

Ainda em 1922, realizou-se o Congresso Nacional dos Práticos, entre 30 de setembro e 07 de outubro, na cidade do Rio de Janeiro, então Distrito Federal. Iniciou-se exatamente um mês e meio antes da investidura de Artur Bernardes, já eleito presidente, mas ainda não empossado. Tal evento reuniu médicos com larga experiência profissional e significativo reconhecimento público, que ocupavam cargos de direção na área da saúde pública e da assistência médica pública e filantrópica ${ }^{26: 27-37}$.

No Congresso Nacional dos Práticos foram identificadas três arenas de disputa entre médicos e outros profissionais que atuavam na área da saúde, dentre eles médicos vs. enfermeiras-visitadoras. 0 objetivo básico era limitar o campo de prática destas atividades para garantir a soberania e a autoridade do médico no mercado de serviços da saúde ${ }^{26: 63}$.

0 Congresso dos Práticos destaca-se exatamente no momento em que as enfermeiras norte-americanas já haviam chegado ao Brasil, mas a escola ainda não começara a funcionar. Ethel Parsons esteve no Congresso dos Práticos apresentando o relatório "As Enfermeiras de Saúde Pública", onde, inicialmente, resgata a história da enfermagem desde os primórdios até 0 advento de Florence Nightingale, que, no seu entender, 'lançou' os fundamentos da arte da enfermagem moderna. Parsons finalizou apresentando propostas direcionadas para o reconhecimento da Escola de Enfermagem prestes a ser instituída, e para a garantia do monopólio dos serviços de enfermagem às futuras enfermeiras ${ }^{26: 74-75}$.

\section{O RELATÓRIO GOLDMARK E A ORGANIZAÇÃO DO SABER E DO FAZER NA ENFERMAGEM DE SAÚDE PÚBLICA NA CAPITAL DA REPÚBLICA}

Em dezembro de 1918, nos EUA, a convite da Fundação Rockefeller, foi promovida em Nova York uma conferência de pessoas interessadas no desenvolvimento da enfermagem de saúde pública. No encontro, discutiu-se o status da enfermagem de saúde pública nos EUA e o nível educacional desejável para 0 treinamento necessário para o seu pessoal. Como resultado desta discussão, foi elaborado um pedido ao presidente da Fundação Rockefeller, através de um comitê, para estudar as questões focadas, como o curto período de formação, visando também preparar uma proposta definitiva para um curso de treinamento destinado às enfermeiras de saúde pública, a partir de suporte financeiro provido pela Fundação. Este grupo viria compor, em janeiro de 1919, o comitê para estudo da educação em enfermagem ${ }^{14: 09}$.

Em março de 1919, este comitê, denominado Comitê para o Estudo da Educação em Enfermagem de Saúde Pública, elegeu como presidente do grupo o Professor C.E.A. Winslow. A condução das investigaç̃̃es ficou a cargo da eminente pesquisadora e assistente social, Miss Josephine Goldmark, cuja popularidade levouIhe, em 1919, a tornar-se secretária do Comitê da Fundação Rockefeller para o Estudo da Educação em Enfermagem ${ }^{14: 10}$.

Porém, em fevereiro de 1920, novamente a convite da Fundação Rockefeller, foi promovida uma segunda conferência de educação em enfermagem. Nesta oportunidade, a discussão focalizou o treinamento apropriado de enfermeiras empregadas, não apenas em saúde pública, mas em hospitais e em serviços privados. Sendo assim, por solicitação da Fundação, o Comitê mudou seu objetivo central, de enfermagem de saúde pública para uma abordagem geral da educação em enfermagem ${ }^{14: 11}$.

0 relatório conclusivo, denominado Nursing and Nursing Education in United States, datado de 1923, usualmente conhecido como Relatório Winslow-Goldmark, foi competente em estabelecer os avanços da educação em Enfermagem; particularmente através do estabelecimento de afiliações universitárias e procedimentos de acreditação nacional ${ }^{14}$.

0 Relatório Goldmark inicia-se com uma Nota Introdutória, o relatório do Comitê e o relatório da Secretária, onde são 
abordados aspectos do relatório e que contém, de forma sintetizada, informações sobre todos os capítulos. 0 relatório abrangeu os grandes temas da enfermagem norteamericana, organizados em duas partes, A e B. A primeira, denominada Funções da Enfermeira, destacou as seguintes áreas: Enfermagem de Saúde Pública, a Enfermeira nos Serviços Privados e a Enfermeira nas Instituições. Para efeito deste estudo, selecionamos os pontos relativos à enfermagem de saúde pública, aqui destacados no Quadro 1. A Parte B do relatório, denominada Treinamento da Enfermeira, abrangeu os temas: 0 Hospital Escola de Enfermagem, Cursos de Treinamento para Enfermagem Subsidiária, Escola Universitária de Enfermagem e Cursos de Pós-Graduação. Estas temáticas subsidiarão outras análises, em estudos posteriores.

\section{Quadro 1:}

Distribuição dos assuntos no Relatório Goldmark relativos à enfermagem de saúde pública, EUA, 1923.

\begin{tabular}{|c|c|}
\hline \multicolumn{2}{|r|}{ Parte A - Funções da Enfermeira } \\
\hline $\begin{array}{l}\text { Enfermagem } \\
\text { de Saúde Pública }\end{array}$ & $\begin{array}{l}\text { As novas tendências no trabalho de Saúde pública. } \\
\text { Algumas realizações da enfermagem na Saúde Pública. } \\
\text { Oportunidade e método de pesquisa: } \\
\text { um estudo intensivo. } \\
0 \text { campo da enfermagem na Saúde Pública: } \\
\text { alguns dias típicos. } \\
\text { Organização e administração das agências } \\
\text { de enfermagem de Saúde pública. } \\
\text { Sucessos e falhas. } \\
\text { Enfermagem industrial. }\end{array}$ \\
\hline
\end{tabular}

Fonte: Relatório Goldmark - Acervo CEDOC da EEAN/UFRJ.

Já havia, no início do século XX, nos EUA, um movimento de saúde pública, na tentativa de se ter um avanço nas condições sanitárias. Com o decorrer dos anos, a preocupação com a saúde ia aumentando e o debate acerca do papel da enfermeira de saúde pública, já existente nos EUA, passou a ser mais discutido. E foi dentro deste contexto que o Relatório Goldmark foi desenvolvido, a partir do final da década de 1910.

Com a ida do sanitarista brasileiro, Dr. Carlos Chagas, conhecedor dos resultados de um serviço de enfermagem moderna de saúde pública, aos EUA, em 1921, pode este acompanhar o desenvolvimento da enfermagem de saúde pública que por lá ocorria. Com um grande desejo de instituir no Brasil um serviço de enfermagem, Carlos Chagas solicitou auxilio ao International Health Board, que atendeu ao seu apelo enviando ao país, no mesmo ano, a enfermeira americana Ethel Parsons, o que viria a caracterizar posteriormente a Missão Parsons ${ }^{11: 14}$.

A partir das relações evidenciadas no Quadro 2 foi constatado que se organizou, em 1922, o Serviço de Enfermeiras $^{\mathrm{e}}$ no DNSP, que incluía todas as atividades de enfermagem, e que estava na mesma linha hierárquica, de acordo com a estrutura administrativa, das inspetorias médicas.

\section{Quadro 2:}

Aspectos do Relatório Goldmark relacionados ao serviço de enfermagem no DNSP.

\begin{tabular}{|c|c|}
\hline Relatório Goldmark & $\begin{array}{c}\text { Enfermagem de Saúde Pública } \\
\text { - DNSP }\end{array}$ \\
\hline $\begin{array}{l}\text { Movimento de Saúde Pública } \\
\text { existente nos EUA. }\end{array}$ & $\begin{array}{l}\text { Estabelecimento de um Serviço de } \\
\text { Enfermeiras no DNSP durante a } \\
\text { Reforma Carlos Chagas. }\end{array}$ \\
\hline $\begin{array}{l}\text { Maior quantidade e qualidade de } \\
\text { enfermeiras: fundamental para o } \\
\text { movimento de saúde pública. }\end{array}$ & $\begin{array}{c}\text { Criação da Escola de Enfermeiras do } \\
\text { DNSP: formar enfermeiras de alto } \\
\text { padrão. }\end{array}$ \\
\hline $\begin{array}{l}\text { Educação Popular: estratégia, } \\
\text { princípio e fundamento. }\end{array}$ & $\begin{array}{l}\text { Realização de educação sanitária } \\
\text { pelas enfermeiras de saúde pública. }\end{array}$ \\
\hline $\begin{array}{l}\text { Contato pessoal direto mais } \\
\text { eficaz. Enfermeira de saúde } \\
\text { pública: mensageiro da saúde. }\end{array}$ & $\begin{array}{c}\text { Organização das enfermeiras de saúde } \\
\text { pública a serem formadas na Escola do } \\
\text { DNSP, por distritos e residências. }\end{array}$ \\
\hline $\begin{array}{l}\text { Ensinar e Cuidar: associados } \\
\text { renderiam maiores resultados. }\end{array}$ & $\begin{array}{c}0 \text { serviço das enfermeiras de saúde } \\
\text { pública incluía cuidados de } \\
\text { enfermagem e de educação sanitária, } \\
\text { para os quais elas eram preparadas } \\
\text { no Hospital Geral de Assistência. }\end{array}$ \\
\hline $\begin{array}{l}\text { Miss Lílian Clayton: integrante do } \\
\text { Comitê. Defendia a idéia de que, } \\
\text { para uma profissão se } \\
\text { desenvolver, eram necessárias } \\
\text { uma Associação e uma Revista }\end{array}$ & $\begin{array}{l}\text { Fundação, em } 12 \text { de agosto de } \\
\text { 1926, da Associação Brasileira de } \\
\text { Enfermeiras Diplomadas. }\end{array}$ \\
\hline
\end{tabular}

Fonte: Relatório Goldmark - Acervo CEDOC da EEAN/UFRJ; Carvalho, 1976; Fontenelle, 1941; Fraenkel, 1934; Parsons, 1927.

Este foi, de fato, o primeiro passo para a adaptação do sistema norte- americano no Brasil. 0 Brasil era o primeiro país a criar um serviço de enfermagem em um departamento de saúde nacional. Nesta época, era comum a criação deste tipo de serviço em departamentos estaduais, como nos EUA ${ }^{8}$.

Diante do movimento de saúde pública existente nos EUA, chegouse aum acordo de que uma maior quantidade equalidade das enfermeiras seriam fundamentais para o sucesso completo deste movimento ${ }^{27}$.

Baseado neste aspecto do Relatório Goldmark, pode-se citar como reflexo do mesmo a criação da Escola de Enfermeiras do DNSP, em 1923.

"Não existindo em todo o país, nem na América do Sul, uma escola capaz de preparar enfermeiras profissionais, o primeiro passo não podia deixar de ser o estabelecimento de uma escola-padrão, nos moldes das mais modernas existentes nos Estados Unidos. Da eficiência do serviço das enfermeiras, preparadas por esta escola, depende o sucesso do magnífico empreendimento"11:14.

Os principais problemas de saúde que existiam nos EUA, à época do desenvolvimento do estudo que resultaria no Relatório Goldmark, tais como a mortalidade infantil e a tuberculose, poderiam ser resolvidos apenas com higiene pessoal, ou seja, uma alteração diária nos hábitos individuais. Tais mudanças nos hábitos diários das pessoas dependiam de um único fato - educação. A educação popular 
era estratégia, princípio e fundamento do movimento de saúde pública dos EUA, e defendida pelo Relatório Goldmark para que houvesse 0 avanço do mesmo ${ }^{27}$.

Tal fundamento veio a influenciar o serviço de enfermeiras no DNSP:

"Começou-se a compreender quão mais valiosa é a persuasão, a educação, a propaganda, em lugar da coação. Em vez de obrigar, esclarecer; em vez de intimar, instruir; em vez de multar, insistir. Esse exemplo nos veio principalmente da Inglaterra e dos Estados Unidos"25: 20 .

Diante dos novos objetivos educacionais, dever-se-ia chegar a um consenso quanto a um método eficaz de propagar tal educação. 0 jornal, o rádio, a conferência pública, ajudavam a preparar o terreno e fazer sucesso mais fácil. Contudo, a última vitória sobre a ignorância era raramente atingida de tal modo nos EUA. 0 contato pessoal direto com as condições de vida individual da população era essencial para o sucesso de uma matéria tão fielmente pessoal quanto a higiene. Procurou-se durante anos um missionário ideal para levar a mensagem de saúde para dentro dos lares. Encontrou-se este mensageiro da saúde na enfermeira de saúde pública ${ }^{27}$.

No DNSP, a enfermeira de saúde pública a ser formada na Escola de Enfermeiras, recém-criada, tornar-se-ia a figura central do movimento sanitário brasileiro ${ }^{8}$.

Uma questão intensamente debatida pelo Comitê que constituía o Relatório Goldmark era se, além da educação acerca das noções de higiene, a enfermeira de saúde pública deveria ou não promover o cuidado daqueles que deste necessitavam. Acreditava-se que o cuidado era o mais importante trunfo da enfermeira de saúde pública. 0 cuidado era uma estratégia para a educação de saúde, no sentido de impulsionar psicologicamente, aumentando a efetividade das ações educativas. Concluiu-se, portanto, que ensinar e cuidar renderia os maiores resultados ${ }^{27}$.

E, segundo Ethel Parsons, superintendente geral do Serviço de Enfermeiras:

"Todo o serviço prestado pelo pessoal do Serviço de Enfermeiras é de cuidados de enfermagem e de educação sanitária, e nunca, de maneira alguma, ultrapassa a linha de demarcação da ética nas atribuições do médico. Primeiro, e sempre, devem as enfermeiras de saúde pública aprender que o seu dever é executar as ordens médicas, notificar ao médico inteligentemente os sintomas e condições encontrados, prestar cuidados de enfermagem aos doentes a domicilio, e ensinar aos doentes e suas famlilias os princípios de prevenção das doenças e de uma vida sadia, aprovados pelas mais científicas descobertas modernas"8:20-21.

Miss Lillian Clayton' ${ }^{9}$, enfermeira americana que fazia parte do Comitê para o estudo da educação em enfermagem, que resultou no Relatório Goldmark, defendia a idéia de que "para uma profissão se desenvolver e progredir, era necessário ter, além de uma escola, uma Associação e uma Revista". De vocação missionária, fez da prestação de cuidados aos pacientes e da formação de enfermeiras o principal objetivo de sua vida. A influência que exerceu sobre muitas centenas de jovens,

como Edith de Magalhães Fraenkel, sua discípula, foi das mais elevadas e edificantes ${ }^{28: 14}$.

Como reflexo desta influência, houve, em 1926, a fundação da Associação Brasileira de Enfermeiras Diplomadas $^{h}$, organizada graças aos esforços de Mrs. Ethel Parsons e D. Edith Fraenkel28:22.

Quadro 3:

Aspectos do Relatório Goldmark relacionados ao ensino de enfermagem no DNSP.

\section{Relatório Goldmark \\ Enfermagem de Saúde} Pública - DNSP

Requerimento de entrada na escola: Requerimento de entrada na escola conclusão do ensino secundário ou diploma de Escola Normal ou uma equivalente. educação equivalente.

Tempo do curso: 28 meses. Tempo do curso: 2 anos e 4 meses, divididos em 5 séries.

Correlação do trabalho prático com Instruções teórica e prática, feitas a instrução teórica. simultaneamente.

Necessária uma pós-graduação para As quatro primeiras séries especializar-se em Saúde Pública. constituirão a parte geral do curso € a última será destinada às especializações.

As alunas teriam direito a 2 meses As alunas teriam direito a dois de férias anualmente. 0 dia de meios dias de descanso por semana trabalho não deveria exceder $8 h$. e uma quinzena de férias anualmente. Serviço diário de $8 \mathrm{~h}$ obrigatório.

Fonte: Relatório Goldmark - Acervo CEDOC da EEAN/UFRJ; Decreto n 16.300, 1923; Parsons, 1927.

A criação da Escola de Enfermeiras do DNSP, em 1923, por influência do Relatório Goldmark, representou uma estratégia importante para a implementação dos aspectos do mesmo na organização dos fatores educacionais a serem implementados no Brasil (Quadro 3). A Escola de Enfermeiras do DNSP teve como primeira diretora a enfermeira norte-americana Clara Louise Kieninger e como primeira instrutora de alunas Annita Lander, que ocuparam os cargos até 1925, quando, então, assume a segunda diretora, Miss Geneviève Dennhardt, e a segunda instrutora, a enfermeira brasileira Edith Fraenkel. Essa substituição constitui o marco inaugural da participação das enfermeiras brasileiras em posições estratégicas nos órgãos de enfermagem do DNSP7: 85-96.

Em primeiro lugar, o Relatório Goldmark afirmava que a escola de treinamento, a qual tinha o propósito de educar enfermeiras capazes de cuidar de doenças agudas, ir para a enfermagem de saúde pública ou atuar como supervisoras, deveria requerer para a entrada de alunas a conclusão do ensino secundário ou equivalente. Tal fato serviria para uma melhor organização dos cursos além de atrair candidatas de qualidade.

Segundo Parsons, desde o princípio ficou resolvido só aceitar para a Escola de Enfermeiras do DNSP alunas que tivessem diploma de Escola Normal ou uma educação equivalente $e^{8: 12}$.

0 tempo do curso ideal para capacitar enfermeiras de qualidade foi estabelecido pelo Relatório Goldmark como um período de 28 meses. Concluiu-se que seria extremamente 
necessário que o curso visasse à correlação do trabalho prático com a instrução teórica ${ }^{27}$.

Este fato veio a influenciar na organização da Escola de Enfermeiras do DNSP, refletindo no decreto $n^{\circ} 16.300 / 1923$, que dizia que o curso da Escola de Enfermeiras visaria instruções teórica e prática, feitas simultaneamente, e seria de 2 anos e 4 meses, divididos em 5 séries.

A enfermeira norte-americana Dennhardt (segunda diretora da Escola), que já incorporava as recomendações do Relatório Goldmark, no sentido de uma melhor relação teoria-prática no currículo do curso de enfermagem, como suas colegas americanas já haviam feito nos EUA, resistia aos insistentes apelos dos médicos, que procuravam suprir as deficiências no campo hospitalar utilizando as alunas de enfermagem como mão-de- obra ${ }^{7: 100}$.

0 curso de 28 meses, discutido anteriormente, forneceria a completa educação para a estudante que desejasse obter 0 diploma de enfermagem para atuar em hospitais, serviço particular ou outras instituições. 0 Comitê que trabalhou no estudo que resultou no Relatório Goldmark concluiu que, para a enfermeira que desejasse se especializar dentro de atividades mais específicas e avançadas, como a de enfermagem em saúde pública, supervisão hospitalar ou educação em enfermagem, seria desejável um período mais longo de treinamento de pós-graduação ${ }^{27}$.

Pelo Decreto $n^{\circ} 16.300 / 1923$, na Escola de Enfermeiras do DNSP, as quatro primeiras séries constituiriam a parte geral do curso, e a última seria destinada às especializações: enfermagem clínica, enfermagem de saúde pública ou administração hospitalar.

0 curso de 28 meses discutido no Relatório Goldmark deveria começar com um termo preliminar de 4 meses de treinamento. Aí, então, deveria seguir um período de 24 meses (incluindo 2 meses de férias) devotados a um curso cuidadosamente progressivo e graduado na teoria e prática de enfermagem, correlatas, e com a eliminação de serviços de rotina, sem valor educacional. Enfatizou-se que o dia de trabalho, incluindo serviço de enfermaria e períodos de sala de aula, não deveria exceder 8 horas. A semana de trabalho não deveria exceder 48 horas, e preferivelmente 44 horas $^{27}$.

Este fato se diferenciou em alguns aspectos na Escola de Enfermeiras do DNSP, já que, de acordo com o decreto $\mathrm{n}^{\circ}$ 16.300/1923, as alunas seriam obrigadas a um serviço diário de 8 horas, no Hospital Geral de Assistência ou em outro estabelecimento de assistência, para cujo serviço fossem destacadas. As alunas teriam direito a dois meios dias de descanso por semana e a uma quinzena de férias anualmente.

\section{Quadro 4:}

Aspectos do Relatório Goldmark relacionados às características da Enfermeira de Saúde Pública no DNSP.

\begin{tabular}{|cc|}
\hline Relatório Goldmark & $\begin{array}{c}\text { Enfermagem de Saúde } \\
\text { Pública - DNSP }\end{array}$ \\
\hline Mulheres, jovens, de capacidade & $\begin{array}{c}\text { Mulheres, jovens, solteiras, de classe } \\
\text { cultural, com educação sólida e ampla. social elevada. Alunas com os mais } \\
\text { elevados requisitos pessoais. } \\
\text { Mulheres com a mais elevada base } \\
\text { social e de instrução. Vocação para } \\
\text { a arte de enfermeira. }\end{array}$ \\
Fonte: Relatório Goldmark -Acervo CEDOC da EEAN/UFRJ; Decreto $n^{\circ} 16.300,1923 ;$ Parsons,
\end{tabular}
1927; Sauthier e Barreira, 1999.
A partir da análise do Quadro 4, podem-se notar algumas características básicas consideradas pelo Relatório Goldmark como necessárias à Enfermeira de Saúde Pública, como, ser mulher, jovem, com capacidade natural (inteligência) e uma educação sólida e ampla (capital cultural elevado).

"Tal enfermeira estabelece-se na confiança de sua comunidade, tanto que ela se torna seu conselheiro fiel e melhor amigo, cuidando do doente, assegurando assistência médica, aconselhando na higiene, resolvendo dificuldades de centenas de tipos com um toque de uma mão prática"27.

Pode-se notar uma grande semelhança, fruto da influência do Relatório Goldmark, nas características consideradas ideais e exigidas para a aluna que desejasse se candidatar à Escola de Enfermeiras do DNSP: mulheres, jovens, solteiras, de classe social elevada ${ }^{7: 66-81}$ além de alunas com os mais elevados requisitos pessoais, com vocação para a arte de enfermeira ${ }^{8}:{ }^{1218}$. Tal influência teve reflexo também no decreto $n^{\circ} 16.300 / 1923$, que dizia:

"Aceita como candidata, deverá a pretendente à matrícula encher uma Folha de Admissão, com declaração do nome, naturalidade, filiação e residência, juntando os seguintes documentos: certidão de idade, por onde fique provado não ter menos de 20 nem mais de 35 anos; documento que prove ser brasileira; atestado oficial do DNSP, que prove ter sido recentemente vacinada contra a varíola; atestado passado por médico do Hospital Geral da Assistência, no qual se declare não sofrer de doença contagiosa, nem de defeito físico ou funcional que a inabilite para os trabalhos de enfermeira; atestado de boa conduta, passado pelas autoridades policiais competentes ou por duas pessoas idôneas, a juízo da diretora da escola e da superintendência geral do Serviço de Enfermeiras; diploma de uma escola normal, ou documento, que prove ter instrução secundária equivalente".

A exigência do diploma de uma escola normal vinha ao encontro dos interesses do campo sanitário, que necessitava de candidatas à enfermeira de saúde pública com capital cultural significativo, tendo em vista que, na visão de Carlos Chagas, estas agentes, além de educar os princípios da boa saúde às mães, deveriam decodificar a linguagem técnica dos médicos e das repartições sanitárias por palavras do senso comum nos lares ${ }^{29}$. Assim, a enfermeira de saúde pública deveria ter a função de mediadora das intencionalidades contidas nas ações prescritas pelos sanitaristas para enfrentar os principais problemas de saúde, como também desempenhava um papel de divulgadora da ideologia do DNSP.

Diferentemente da tradição norte-americana, a busca de mulheres de famílias tradicionais para as primeiras turmas da escola ligada ao serviço de enfermeiras, que Carlos Chagas criara, ganharia a preocupação dos dirigentes brasileiros. Não era um critério absoluto. Havia moças de famílias mais humildes, igualmente, basta examinar as fichas das bolsistas no exterior para se chegar a esta conclusão. Mas parece que havia uma atitude refletida por parte dos dirigentes brasileiros, entre eles Carlos Chagas e Plácido Barbosa, de que numa sociedade profundamente hierarquizada como a do Brasil de 1920, uma profissão só teria condições de legitimar-se se contasse com membros das elites ${ }^{6: 132}$. 


\section{CONSIDERAÇÕES FINAIS}

As endemias e epidemias impulsionaram o movimento sanitário em fins da década de 1910, com destaque para a gripe espanhola. Tal movimento, designado Reforma Sanitária Carlos Chagas, teve como fato estratégico a criação do Departamento Nacional de Saúde Pública, no âmbito do Estado brasileiro.

0 interesse de uma parte dos sanitaristas brasileiros, que ocupavam posições privilegiadas na Reforma Sanitária, pela convergência do modelo de ensino de enfermagem dos EUA para a nova Escola de Enfermeiras do DNSP, deu-se concomitante ao estudo denominado Nursing and Nursing Education in United States, conhecido como Relatório Goldmark, tendo ambos os projetos o mesmo pilar de sustentação, a Fundação Rockefeller.

A enfermeira de saúde pública passou a ser a agente de persuasão nas estratégias de educação sanitária nas diversas

\section{Referências}

1. Fallante BSC, Barreira IA. Significados da visita domiciliar realizada pelas enfermeiras de saúde pública nas décadas de 20 e 30. Esc Anna Nery Rev Enferm 1998 dez; 2(3): 72 - 85.

2. Faria LR. Os primeiros anos da reforma sanitária no Brasil e a atuação da Fundação Rockefeller: 1915-1920. Physis 1995; 5(1): 109- 27.

3. Fundação Nacional de Saúde- FUNASA. 100 anos de Saúde Pública: a visão da FUNASA. Brasília (DF); 2004.

4. Decreto $\mathrm{n}^{0} 3.987$, de 02 de janeiro de 1920. Dispõe sobre a reorganização dos serviços da saúde pública. Rio de Janeiro (DF); 1920. Coleção das Leis da República dos Estados Unidos do Brasil

5. Decreto $n^{0} 14.354$, de 15 de setembro de 1920. Dispõe sobre a aprovação do regulamento para o Departamento Nacional de Saúde Pública, em substituição do que acompanhou o Decreto $n^{\circ}$ 14.189, de 26 de maio de 1920. Rio de Janeiro (DF); 1920. Coleção das Leis da República dos Estados Unidos do Brasil.

6. Santos LAC, Faria LR. A cooperação internacional e a enfermagem de saúde pública no Rio de Janeiro e São Paulo. Horizontes 2004 jul/dez; 22(2): 123-50.

7. Sauthier J, Barreira IA. As enfermeiras norte-americanas e o ensino da enfermagem na capital do Brasil: 1921-1931. $1^{\text {a }}$ ed. Rio de Janeiro (RJ): EEAN/UFRJ; 1999.

8. Parsons E. A enfermagem moderna no Brasil: 1927. [fac-símile]. Esc Anna Nery Rev Enferm 1997 jul; 1 ( $n^{\circ}$ lanç).

9. Moreira MCN. A Fundação Rockfeller e a construção da identidade profissional de enfermagem no Brasil na Primeira República. Hist Cienc Saude-Manguinhos 1998/1999 nov/fev; 5(3): 621-29.

10. Carvalho AC. Orientação e ensino de estudantes de enfermagem no campo clinico [tese de doutorado]. São Paulo (SP): Universidade de SãoPaulo; 1972.

11. Fraenkel E. Histórico do serviço de enfermeiras do Departamento Nacional de Saúde Pública. An Enferm 1934 abr/out; 2(4).

12. Fausto B. História concisa do Brasil. São Paulo (SP): EdUSP; 2001.

13. Costa NR. Lutas urbanas e controle sanitário: origens das políticas de saúde no Brasil. Petrópolis (RJ): Vozes; 1986.

14. Silva Junior OC. A profissionalização da enfermagem nos Estados Unidos da América do Norte: a proposta educativa do Relatório Goldmark, 1923. [tese de pós-doutorado]. Rio de Janeiro (RJ): Instituto de Medicina Social/ UERJ; 2003. ações empreendidas pelo DNSP, e, portanto, a criação e a organização do Serviço e da Escola de Enfermeiras do Departamento passaram a ser espaços privilegiados de discussão sobre o saber e o fazer da enfermagem de saúde pública na década de 1920.

$\mathrm{Na}$ recém-criada enfermagem de saúde pública, eminentemente feminina, o cuidado de enfermagem e a educação sanitária eram interligados, pois acreditavase que o primeiro era mais um trunfo na direção da efetividade das ações educativas.

Quanto ao ensino, a influência e a gerência das enfermeiras norte-americanas Ethel Parsons e Clara Louise Kieninger, respectivamente, na Superintendência de Enfermagem e na direção da Escola de Enfermeiras do DNSP, garantiram a implementação das recomendações do Relatório Goldmark para 0 ensino de enfermagem, consolidado nos decretos e regulamentos deste Departamento.

15. Barreira IA. Memória e história para uma nova visão da enfermagem no Brasil. Rev Latino-am Enfermagem 1999 jul; 7(3): 87-93.

16. Alves-Massaotti AJ, Gewandsznajder F. 0 método em ciências sociais: pesquisa quantitativa e qualitativa. São Paulo (SP): Pioneira; 1998.

17. Cardoso CF, Vainfas R. Domínios da história: ensaios de teoria e metodologia. $5^{a}$ ed. Rio de Janeiro (RJ): Campus; 1997.

18. Felix LO. História e memória: a problemática da pesquisa. Passo Fundo (RS): EDIUPF; 1998.

19. Cotrim G. História global: Brasil e geral. $6^{\text {a }}$ ed. São Paulo (SP): Saraiva; 2002.

20. Linhares MY, organizadora. História geral do Brasil. $6^{\mathrm{a}}$ ed. Rio de Janeiro (RJ): Campos; 1990.

21. Hochman G. Regulando os efeitos da interdependência: sobre as relações entre saúde pública e construção do Estado (Brasil 1910 1930). Est Hist 1993; 6(11): 40 - 61.

22. Lima NT, Hochman G. Condenado pela raça, absolvido pela medicina: o Brasil descoberto pelo movimento sanitarista da Primeira República. In: Maio MC, Santos RV, organizadores. Raça, ciência e sociedade. Rio de Janeiro (RJ): FIOCRUZ/CCBB; 1996.

23. Santos LAC. 0 pensamento sanitarista na Primeira República: uma ideologia de construção da nacionalidade. Rev Cienc Soc 1985; 28(2): $193-210$.

24. Baptista SS. Trajetória das escolas de enfermagem na sociedade brasileira. Esc Anna Nery Rev Enferm 1997 dez; 1(2): 88.

25. Fontenelle JP. A enfermagem de Saúde Pública: sua creação e desenvolvimento no Rio de Janeiro. Rio de Janeiro (RJ): Canton \& Reile; 1941.

26. Pereira Neto AF. Ser médico no Brasil: o presente no passado. Rio de Janeiro (RJ): FIOCRUZ; 2001.

27. Report of the Committee for the Study of Nursing Education. Nursing and Nursing Education in the United States. New York(USA): Macmillan Company; 1923.

28. Carvalho AC. Associação Brasileira de Enfermagem:1926-1976. Documentário. Brasilia (DF): ABEn; 1976.

29. Departamento Nacional de Saúde Pública. A enfermeira moderna: appello às moças brasileiras. Inspectoria de Demographia Sanitária, Educação e Propaganda. Rio de Janeiro (DF); 1922. 


\section{Notas}

Trabalho gratificado com o prêmio $A$ Lâmpada, $1^{\circ}$ lugar, na $10^{\text {a }}$ Jornada Nacional de História da Enfermagem - Núcleo de Pesquisa de História da Enfermagem Brasileira (NUPHEBRAS), da Escola de Enfermagem Anna Nery, da UFRJ.

bPelo Decreto ${ }^{\circ}{ }^{15.799}$, de 10 de novembro de 1922, foi autorizada a criação da Escola de Enfermeiras, porém, neste estudo será levado em consideração o ano de 1923 como ano de criação por ser o ano em que de fato há o início das atividades. A inauguração da Escola de Enfermeiras do DNSP ocorreu em 19 de fevereiro de 1923.

'A Escola de Enfermeiras do DNSP, pelo Decreto n 17.268, de 31 de março de 1926, passou a chamar-se Escola de Enfermeiras D. Anna Nery (Fraenkel, 1934, p.15).

dAntônio Augusto de Azevedo Sodré (1864-1929) doutorou-se em medicina em 1885 com tese sobre métodos de tratamento da sífilis. Trabalhou como preparador interino de matéria médico-terapêutica (1887), interno de clínica de doenças cutâneas e sifilíticas (1889) e preparador de terapêutica experimental (1890). Em 1894 conquistou a cátedra de patologia interna da Faculdade de Medicina do Rio de Janeiro, da qual foi diretor em 1911-1912. Presidiu o IV Congresso Médico Latino-Americano, realizado no Rio de Janeiro em 1909, e representou o Brasil no II Congresso Internacional Americano, em Buenos Aires (1903). Foi professor de medicina legal da Faculdade de Direito, presidente da Academia Nacional de Medicina, prefeito do Distrito Federal (1916-1917) e deputado federal pelo estado do Rio de Janeiro. Publicou vários livros e artigos sobre política sanitária e educação, e sobre enfermidades como cólera, doenças intestinais, tuberculose, malária, ancilostomíase e, especialmente, febre amarela, que estudou em colaboração com Miguel Couto. Azevedo Sodré teve papel destacado na vida médica brasileira. Participou da Liga Pró-Saneamento, foi um dos fundadores da Sociedade de Medicina e Cirurgia do Rio de Janeiro, criou a Sociedade dos Internos dos Hospitais e foi diretor-fundador de 0 Brazil-Medico, Revista Semanal de Medicina e Cirurgia, durante muitos anos o principal periódico médico do país.

eA criação oficial do Serviço de Enfermeiras só se efetivou pelo decreto $n^{\circ} 16.300$, de 31 de dezembro de 1923, sendo a sua sede estabelecida numa grande sala do pavilhão anexo ao próprio Departamento (Fraenkel, 1934, p. 14).

'Os trechos referentes ao Relatório Goldmark, citados ao longo deste trabalho, foram traduzidos pelos autores deste estudo.

'Lillian Clayton era enfermeira americana, cujo nome está intimamente ligado ao Hospital Geral de Filadélfia, onde foi superintendente do Serviço de Enfermagem, diretora e professora de Ética da Escola de Enfermagem desse hospital. Edith Fraenkel foi formada nessa escola. Fizeram curso de aperfeiçoamento nessa escola várias diplomadas brasileiras a partir de 1925 (Carvalho, 1976, p. 14).

hEsta Associação foi reorganizada em fins de 1928, passando a chamar-se Associação Nacional de Enfermeiras Diplomadas Brasileiras, sendo nessa ocasião registrada juridicamente (Annaes de Enfermagem, out./1934, p. 06). 